\title{
Safety and Effectiveness of Additional Apical Preparation using a Rotary Heat-treated Nickel- Titanium file with Larger Diameter and Minimum Taper in Retreatment of Curved Root Canals
}

\author{
Jader Camilo Pinto $\quad$ Fernanda Ferrari Esteves Torres ${ }^{1} \quad$ Airton Oliveira Santos-Junior ${ }^{1}$ \\ Karina Ines Medina Carita Tavares ${ }^{1}$ Marco Antonio Hungaro Duarte ${ }^{2}$ Juliane Maria Guerreiro-Tanomaru ${ }^{1}$ \\ Mario Tanomaru-Filho' ${ }^{1}$
}

${ }^{1}$ Department of Restorative Dentistry, School of Dentistry, São

Paulo State University, Araraquara, São Paulo, Brazil

${ }^{2}$ Department of Dentistry, Endodontics and Dental Materials, School of Dentistry, University of São Paulo, São Paulo, Brazil

\author{
Address for correspondence Mario Tanomaru-Filho, DDS, \\ PhD, Department of Restorative Dentistry, Araraquara Dental \\ School, São Paulo State University-UNESP, Rua Humaitá, 1680, \\ CEP 14801-903 Araraquara, SP, Brazil (e-mail: tanomaru@uol.com.br).
}

Eur J Dent 2021;15:247-252

\begin{abstract}
Keywords

- Dental pulp cavity

- retreatment

- root canal preparation

- X-ray

microtomography

Objective The aim of this study was to investigate the effect of additional apical preparation using the ProDesign Logic (PDL) 50/.01 rotary heat-treated nickeltitanium (NiTi) file with a larger diameter and minimal taper for retreatment of curved root canals.

Materials and Methods Mesial curved root canals of 12 mandibular molars were prepared using PDL 25/.06 and filled using the continuous wave of condensation technique and $\mathrm{AH}$ Plus sealer. After retreatment using ProDesign S (PDS) 25/.08, PDL 25/.06 and PDL 35/05, a complementary procedure was performed with PDL 50/.01. Microcomputed tomography (micro-CT) scanning was performed before and after retreatment procedures. The cyclic fatigue resistance of unused PDS 25/.08, PDL 25/.06, PDL 35/.05 and PDL 50/.01 instruments $(n=12)$ was evaluated in a stainless-steel device.

Statistical Analysis Data on the volumes of the root canals and the remaining filling materials were submitted to the paired t-test. Cyclic fatigue resistance data was submitted to one-way ANOVA and Tukey's tests ( $\alpha=0.05$ ).

Results Use of PDL 50/.01 decreased the remaining filling materials in the apical third $(p<0.05)$. The root canal volume was similar in the cervical and middle thirds before and after preparation using PDL 50/.01 ( $p>0.05$ ). PDL 50/.01 presented the highest cyclic fatigue resistance $(p<0.05)$.

Conclusions Use of the PDL 50/.01 instrument as an additional apical preparation for retreatment of curved root canals improved filling material removal in the apical third, while maintaining the dentin in the cervical and middle thirds. In addition, PDL 50/.01 presented high-flexural resistance.
\end{abstract}

published online February 23, 2021
DOI https://doi.org/

10.1055/s-0041-1723065 ISSN 1305-7456.
(C) 2021. European Journal of Dentistry.

This is an open access article published by Thieme under the terms of the Creative Commons Attribution-NonDerivative-NonCommercial-License, permitting copying and reproduction so long as the original work is given appropriate credit. Contents may not be used for commercial purposes, or adapted, remixed, transformed or built upon. (https://creativecommons.org/licenses/by-nc-nd/4.0/). Thieme Medical and Scientific Publishers Pvt. Ltd. A-12, 2nd Floor, Sector 2, Noida-201301 UP, India 


\section{Introduction}

Endodontic retreatment in mandibular molars poses greater difficulty owing to the curvature in molar mesial roots. ${ }^{1,2}$ Use of nickel-titanium (NiTi) instruments with larger diameter in curved root canals can lead to deviations and instrument fracture, because of low flexibility ${ }^{3}$ and cyclic fatigue resistance. ${ }^{4}$ However, heat treatments have been developed to optimize the mechanical properties of NiTi instruments. ${ }^{5,6}$ Controlled memory $(\mathrm{CM})$ heat treatment promotes an NiTi alloy martensitic phase at room temperature, ${ }^{7}$ providing greater flexibility and resistance to cyclic fatigue, ${ }^{8}$ thus enabling apical enlargement in curved root canals. ${ }^{9}$

Although mechanized NiTi instruments have been used in endodontic retreatments because of their safety ${ }^{10}$ and effectiveness in removing filling materials, ${ }^{11-14}$ these materials cannot be fully removed from the root canal, ${ }^{15-22}$ especially in the apical third of curved root canals. ${ }^{23}$ Apical enlargement can improve removal of filling materials ${ }^{13}$; however, an increase in the apical preparation of curved root canals using instruments with larger diameter may result in excessive dentin removal..$^{24}$

ProDesign Logic (PDL) and ProDesign S (PDS) (Easy Equipamentos Odontológicos; Belo Horizonte, MG, Brazil) are NiTi rotary instruments with $\mathrm{CM}$ heat treatment. The PDL 50/.01 file has a large tip size and minimal taper, which has been proposed to perform apical enlargement in endodontic retreatments. ${ }^{13}$ Use of PDL size 50/.01 have been found to significantly decrease the amount of filling material in the apical third of curved lateral incisors. ${ }^{13}$ However, there are no studies to date that have evaluated the increase in root canal volume promoted by the PDL $50 / .01$ instrument in retreating curved root canals. In addition, the cyclic fatigue resistance of PDL 50/.01 has not yet been evaluated.

The aim of this study was to use microcomputed tomography (micro-CT) to evaluate the effect of apical enlargement with the PDL 50/.01 instrument in the retreatment of curved mesial root canals of mandibular molars. The cyclic fatigue resistance of the NiTi rotary PDS 25/.08, PDL 25/.06, PDL 35/.05 and PDL 50/.01 instruments was also evaluated. The first and second null hypotheses were that using a PDL 50/.01 instrument after retreatment with PDL 35/.05 would not decrease the amount of remaining filling material, and would not change the root canal volume, respectively. The third null hypothesis was that there would be no difference in the cyclic fatigue resistance among the NiTi rotary instruments evaluated.

\section{Materials and Methods}

\section{Sample Size Calculation}

The tests were performed with a specific $\mathrm{G}^{*}$ Power software program (3.1.7 for Windows, Heinrich Heine, Universität Dusseldorf, Germany). The t-test for two dependent groups was used with an alpha type error of 0.05 and beta power of 0.95 for all the variables. Previous studies were used to determine the specific effect size for the amount of remaining filling material $(2.348)^{12}$ and root canal volumes (1.209)..$^{9} \mathrm{~A}$ total of 12 specimens were indicated as the ideal size required.

\section{Specimen Selection}

After approval of the study by the InstitutionalEthics Committee (64736116.4.0000.5416), 12 human mandibular first and second molars were selected. The inclusion criteria included two independent mesial root canals according to Vertucci's type IV classification, ${ }^{25}$ angle of curvature between $25^{\circ}$ and $35^{\circ}, 1$ and radius of curvature smaller than $10 \mathrm{~mm},{ }^{26}$ as well as complete apical formation, and absence of root fractures, calcifications or internal resorptions. The specimens were selected by a digital radiography system (RVG 6100; Kodak Dental Systems, NY, USA) and micro-CT (SkyScan 1176; Bruker-micro-CT, Kontich, Belgium) used at $35-\mu \mathrm{m}$ voxel size, and the following settings were considered: copper and aluminum filter, exposure time of $87 \mathrm{~ms}$, average of 3 frames, $180^{\circ}$ rotation, 0.5 rotation step, $80 \mathrm{kV}$, and $300 \mu \mathrm{A}$. A total of 12 roots were selected, totaling 24 root canals, including the mesiobuccal and the mesiolingual canals of each root. The root length was standardized at $18 \mathrm{~mm}$, with a tolerance of $\pm 1 \mathrm{~mm}$. The specimens were embedded in silicone (Oranwash; Zhermack, Badia Polesine, Italy) to simulate the periodontal ligament. All the root canals were prepared, filled, and retreated using the same technique, to allow comparison of the variables before and after use of the PDL 50/.01.

\section{Root Canal Preparation}

Conventional access cavities were performed, and the root canals were explored with a size \#10 K-file (Dentsply Sirona Endodontics; Ballaigues, Switzerland). The working length (WL) was established $1 \mathrm{~mm}$ short of the apical foramen. Preparation was performed using PDL 25/.01 operated by a VDW Silver (VDW GmbH; Munich, Germany) electric motor in rotary motion at a speed of $350 \mathrm{rpm}$ and $1 \mathrm{Ncm}$ torque, with in-and-out movements up to the WL. Then, PDL size 25/.06 was used at $600 \mathrm{rpm}$ and $3 \mathrm{Ncm}$ torque, as described above. Each root canal was irrigated with $5 \mathrm{~mL}$ of $2.5 \%$ sodium hypochlorite ( $\mathrm{NaOCl})$ ( $2.5 \mathrm{~mL}$ after use of each file). Final irrigation was performed with $2.5 \mathrm{~mL}$ EDTA under agitation for 3 minutes, and then irrigation using $5 \mathrm{~mL}$ of distilled water.

\section{Root Canal Filling}

The root canals were filled using the continuous wave of condensation technique. Tanari 25/.06 (Tanariman; Manacapuru, AM, Brazil) gutta-percha points were selected according to the tip size and taper measured by a profilometer (Profile Projector Nikon model 6C-2; Nikon, Tokyo, Japan). After radiographic evaluation was made of the selected gutta-percha point adaptation, the point was covered with AH Plus sealer (Dentsply DeTrey GmbH, Konstanz, Germany) and placed in the root canal with a size 25 Lentulo (Dentsply Maillefer, Ballaigues, Switzerland). The thermoplastic plugger from the Termo Pack II System (Easy Equipamentos Odontológicos, Belo Horizonte, MG, Brazil) was used for plasticization, cutting and compaction of the gutta-percha within the apical root canal up to $3 \mathrm{~mm}$ of the 
WL. The thermal injector of the system was used to inject the warmed gutta-percha. Compaction was performed with NiTi condensers (Easy Equipamentos Odontológicos, Belo Horizonte, MG, Brazil). A radiograph was taken to determine the quality of the obturation. Coronal sealing was performed with Coltosol restorative material (Vigodent, Rio de Janeiro, RJ, Brazil), and the roots were kept in an incubator at a temperature of $37^{\circ} \mathrm{C}$ in $95 \%$ humidity for 7 days, to allow the sealer to set.

\section{Root Canal Retreatment}

A VDW Silver electric motor was used in rotary motion at $600 \mathrm{rpm}$ and $3 \mathrm{Ncm}$ torque. In-and-out movements were performed up to the WL. PDS 25/.08 was used to remove the filling from the cervical and middle thirds, and PDL 25/.06 was used to remove the filling from the apical third. The root canals were enlarged with PDL 35/.05 as described above. Each root canal was irrigated with $6 \mathrm{~mL}$ of $2.5 \% \mathrm{NaOCl}$ ( $2 \mathrm{~mL}$ for each instrument). Final irrigation was performed as described in the preparation step.

\section{Supplemental Cleaning Approach}

The PDL 50/.01 was operated with a VDW Silver electric motor in rotary motion at a speed of $350 \mathrm{rpm}$ and $1 \mathrm{Ncm}$ torque, with in-and-out movements up to the WL. The root canals were irrigated with $2 \mathrm{~mL}$ of $2.5 \% \mathrm{NaOCl}$. Final irrigation was performed as previously described.

\section{Micro-CT Scanning and Analysis}

The roots were scanned using micro-CT before and after root canal retreatment, and after apical enlargement with PDL 50/.01. The scanning parameters were copper and aluminum filter, $90 \mathrm{kV}, 278 \mathrm{~mA}$ energy, $180^{\circ}$ rotation, 0.5 rotation step, average of 3 frames, and $8.74 \mu \mathrm{m}$ voxel size. The images obtained were reconstructed using the NRecon software program (v.1.6.3; Bruker-micro-CT) and superimposed by geometric alignment in the Data Viewer software program (v.1.5.1; Bruker-micro-CT). Volumetric analysis was performed in all the root canals using a CTAn software program (v.1.14.4; Bruker-micro-CT) with a specific task list. Root canal volume and remaining filling material were quantified after the retreatment steps. The gray scale range, which is required to recognize each object under study, was determined in a density histogram by using the adaptive threshold method. Representative images were performed using the models obtained by the CTVox software program (v.3.2; Bruker-micro-CT). Evaluation was performed in the apical third and the cervical/middle thirds of the root canals. A value of approximately $9 \mathrm{~mm}$ was determined for the total length analysis, approximately $3 \mathrm{~mm}$ for the apical third, and $6 \mathrm{~mm}$ for the cervical/middle thirds.

\section{Cyclic Fatigue Test}

The cyclic fatigue resistance of unused PDS 25/.08, PDL 25/.06, PDL 35/.05 and PDL 50/.01 instruments was evaluated $(n=12)$. The static bending test was performed in a device simulating an artificial canal with a $60^{\circ}$ angle and 5-mm radius of curvature (-Fig. 1) The instruments were used at $300 \mathrm{rpm}$ and $300 \mathrm{~g} / \mathrm{cm}$ torque of continuous rotary motion, driven by a VDW Silver (VDW Silver, GmbH, Munich, Germany) electric motor. All instruments were rotated until fracture, and WD-40 synthetic oil (WD-40 Multipurpose Product, Brazil) was used to reduce friction. The time to failure was obtained in minutes.

The device used for the tests consisted of an iron base $(50 \times 30 \mathrm{~cm})$ with a fixing support for the low-speed handpiece, in accordance with previous studies. ${ }^{27,28}$ After the instruments had been coupled to the low-speed handpiece, the height of the support was adjusted, so that the instrument could be inserted into the artificial canal without causing stress, thus allowing free rotation. The curvature of the stainless-steel artificial canal was fitted into a cylinder guide made of the same material. A groove served as the guide path for the instrument, which remained curved and free to rotate. During the tests, the instruments were placed, so that $1 \mathrm{~mm}$ of the instrument tip protruded beyond the end of the artificial canal walls, to allow the tip to be visualized, and the moment of instrument fracture to be determined.

\section{Statistical Analysis}

All the data were analyzed with the GraphPad Prism 7.00 statistical software package (GraphPad Software, La Jolla, CA, USA). The data were submitted to the Shapiro-Wilk normality test. The paired t-test was used for comparison of the root canal retreatment before and after PDL size 50/.01 taper preparation. One-way ANOVA and Tukey tests were used to compare instruments for cyclic fatigue. The level of significance was set at $5 \%$ for all the analyses.

\section{Results}

Use of PDL 50/.01 decreased the remaining filling material and increased the root canal volume in the apical third $(p<0.05)$. (-Table 1, - Table 2, and - Fig. 2). The volume of the root canals was similar in the cervical/middle thirds before and after preparation with PDL 50/.01 ( $p>0.05$ ) (-Table 2). PDL 50/.01 had higher cyclic fatigue resistance than PDS 25/.08, PDL 25/.06 and PDL 35/.05 ( $p<0.05$ ) (-Fig. 3).

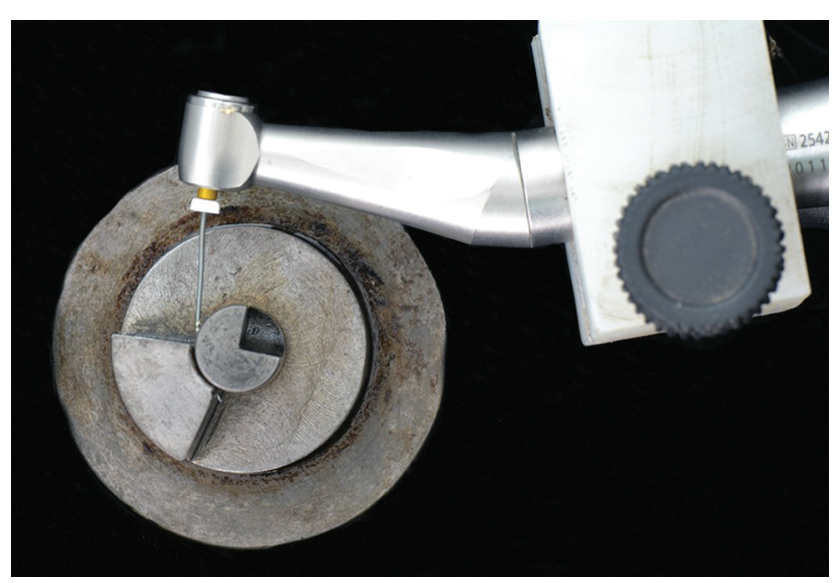

Fig. 1 Representative image of the cyclic fatigue test. 
Table 1 Residual filling material (\%) in the curved root canals before and after the use of PDL 50/.01 and the reduction of residual filling material (\%) (mean and standard deviation)

\begin{tabular}{|l|l|l|l|}
\hline & Before PDL 50/.01 & After PDL 50/.01 & $\begin{array}{l}\text { Reduction in residual filling } \\
\text { material (\%) }\end{array}$ \\
\hline Cervical/middle & $9.876 \pm 2.543^{\mathrm{a}}$ & $9.289 \pm 3.523^{\mathrm{a}}$ & $5.97 \pm 1.54$ \\
\hline Apical & $8.920 \pm 3.230^{\mathrm{a}}$ & $3.895 \pm 1.897^{\mathrm{b}}$ & $56.35 \pm 9.76$ \\
\hline
\end{tabular}

Abbreviations: PDL, ProDesign Logic; PDS, ProDesign S.

Note: Different lowercase letters on same line represent significant intragroup differences $(p<0.05)$.

Table 2 Root canal volume (mm3) in the curved root canals before and after the use of PDL 50/.01 and root canal volume increase (\%) (mean and standard deviation)

\begin{tabular}{|l|l|l|l|}
\hline & Before PDL 50/.01 & After PDL 50/.01 & Volume increase \\
\hline Cervical/middle & $3.952 \pm 0.208^{\mathrm{a}}$ & $4.001 \pm 0.432^{\mathrm{a}}$ & $1.23 \pm 0.32$ \\
\hline Apical & $0.617 \pm 0.105^{\mathrm{b}}$ & $0.861 \pm 0.092^{\mathrm{a}}$ & $39.54 \pm 4.87$ \\
\hline
\end{tabular}

Abbreviations: PDL, ProDesign Logic; PDS, ProDesign S.

Note: Different lowercase letters on same line represent significant intragroup differences $(p<0.05)$.

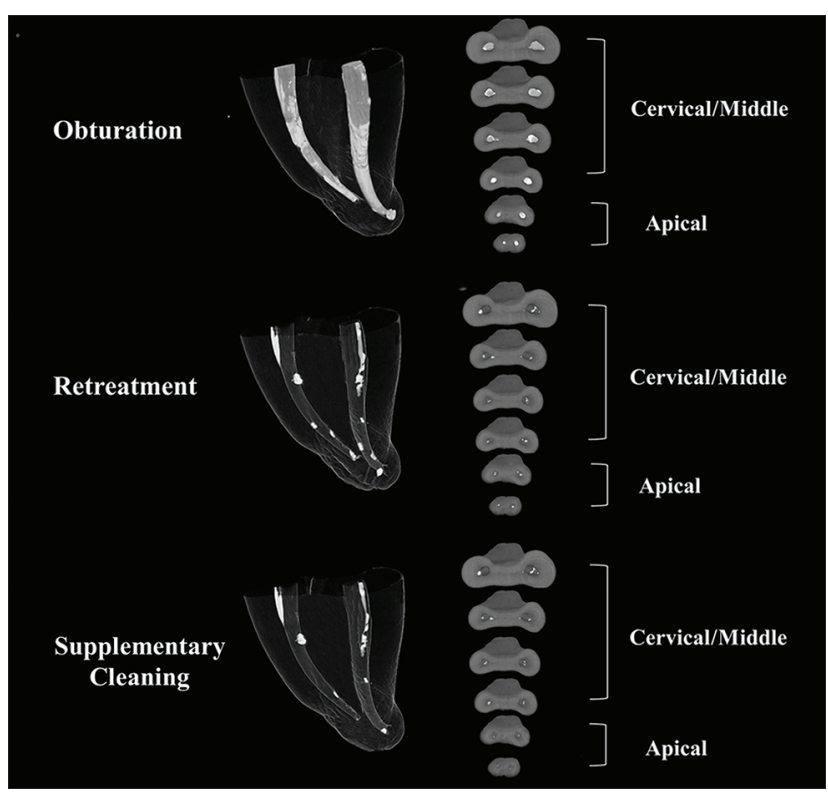

Fig. 2 Three dimensional reconstructions and cross-sectional images of mesial root canals of mandibular molars after the steps of obturation, retreatment, and additional retreatment. Filling material is shown in white.

\section{Discussion}

Endodontic retreatment is the main option when endodontic treatment failure occurs. ${ }^{29}$ However, failure during removal of the filling material may not allow disinfection of the root canal system. ${ }^{12,16}$ The remaining filling material allows the reinfection of the root canal system, leading to the maintenance of periapical peridontitis..$^{30}$ Apical enlargement two sizes larger than the instrument used for root canal preparation is recommended to improve the removal of filling materials. ${ }^{31}$ Therefore, in the present study, root canals were prepared up to size 25/.06 and were enlarged up to size 35/.05 during retreatment. However, corroborating previous investigations, ${ }^{11,13,18}$ the present study

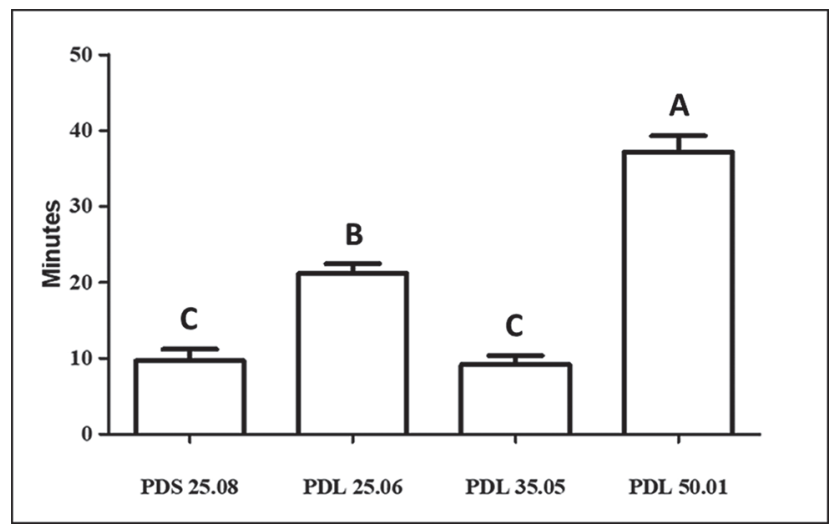

Fig. 3 Means and standard deviations of time up to instrument fracture. Different uppercase letters indicate a statistical intergroup difference $(p<0.05)$.

showed a considerable percentage of filling material inside the root canals, with a mean of $9.87 \%$ and $8.92 \%$ in the cervical/ middle and apical thirds, respectively.

The first null hypothesis was rejected, since the PDL 50/.01 instruments reduced $56.35 \%$ of the remaining filling material in the apical third of the curved mesial root canals of lower molars. Significant reduction in residual material at apical levels in curved root canals after additional apical enlargement is reported..$^{13,32}$ Removal of the remaining filling material probably occurred because greater apical enlargement increases the ability of the instrument to reach the root canal walls. ${ }^{33}$ In addition, the increase in the volume of the apical third after using the PDL $50 / .01$ allows better cleaning of the root canal, favoring the effect of the irrigating solution, ${ }^{34}$ and enhancing root canal disinfection..$^{35}$

Apical enlargement may promote excessive removal of dentin, thus decreasing root strength. ${ }^{24}$ Therefore, the current study assessed the volume of the root canals before and 
after retreatment. Our second null hypothesis was partially accepted, since the volume of the root canals was similar in the cervical/middle thirds before and after preparation using PDL 50/.01. This indicates that this instrument maintains dentin thickness in the danger zone of mandibular molars. The small taper of these instruments allows apical preparation with no dentinal removal in the cervical and middle thirds. The root canal preparation for retreatment using PDL 35/.05 involves a $0.55-\mathrm{mm}$ diameter at $4 \mathrm{~mm}$ from the apical preparation. PDL 50/.01 taper has a diameter of 0.54 at $4 \mathrm{~mm}$ from the apical preparation; therefore, its effect occurs only in the apical third. In addition, the CM heat treatment of this instruments allows root canal enlargement of curved canals with no apical transportation. ${ }^{9}$

The fracture of mechanized NiTi instruments may cause a deleterious effect on root canal disinfection. ${ }^{29}$ Cyclic fatigue fractures occur after repeated tension and compression forces on instruments submitted to motion in curved root canals. ${ }^{36}$ The third null hypothesis of this study was rejected, since PDL 50/.01 showed higher cyclic fatigue resistance than PDL 25/.06, PDL 35/.05 and PDS 25/.08. The minimal taper (.01) of PDL size 50 presents less metallic volume than the other instruments evaluated. Instruments with a larger metal mass volume have lower flexural strength. ${ }^{36}$ PDS and PDL instruments were found to have higher cyclic fatigue resistance than the HyFlex CM, Edge File, and Mtwo systems. ${ }^{8}$

The main limitation of this supplemental cleaning approach using PDL 50/.01 is that this instrument did not provide effective removal of the remaining filling in the cervical and middle thirds of the root canal. Hence, a suggested approach would be to associate the PDL 50/.01 with an effective supplemental cleaning process for the cervical and middle thirds. However, the significant decrease in the remaining filling material in the apical third promoted by PDL 50/.01 has clinical relevance, since cleaning of the apical third is a challenge in retreatment procedures. ${ }^{23,37}$ The apical third of the canal is always more difficult to clean, an aspect worth pointing out, because it represents a critical infection zone prone to development and maintenance of apical periodontitis. ${ }^{38}$

Larger apical enlargement during retreatment procedures decreases the remaining filling material, ${ }^{32}$ reducing endotoxin levels. ${ }^{39}$ On the other hand, preparation of curved mesial root canals using larger diameter instruments may produce excessive dentin removal in the danger zone, reducing tooth resistance. ${ }^{24}$ The present results have shown that apical enlargement with mechanized NiTi instruments having minimal taper, such as PDL 50/.01, seems to be effective in reducing the remaining filling material in the apical third of curved root canals of mandibular molars, with no additional dentin removal in the cervical and middle thirds. Moreover, a low risk of cyclic fatigue fracture was observed for this instrument. However, the protocol evaluated in the current study was not able to remove the filling material completely from the root canals.

\section{Conclusions}

The PDL 50/.01 instrument improved removal of filling material in the apical third when used as a supplemental procedure for retreatment of curved root canals, and it also proved safe in not promoting dentin removal in the cervical and middle thirds. In addition, PDL 50/.01 had high flexural resistance.

\section{Funding}

The study was supported by the São Paulo State Research Foundation (FAPESP, 2018/19665-6, 2017/19049-0 and 2019/22885-0) and Coordenação de Aperfeiçoamento de Pessoal de Nível Superior (CAPES) - Funding Code 001.

\section{Conflict of Interest}

None declared.

\section{References}

1 Schneider SW. A comparison of canal preparations in straight and curved root canals. Oral Surg Oral Med Oral Pathol 1971;32(2):271-275

2 de Pablo OV, Estevez R, Péix Sánchez M, Heilborn C, Cohenca N. Root anatomy and canal configuration of the permanent mandibular first molar: A systematic review. J Endod 2010;36(12):1919-1931

3 Gagliardi J, Versiani MA, de Sousa-Neto MD, Plazas-Garzon A, Basrani B. Evaluation of the shaping characteristics of ProTaper Gold, ProTaper NEXT, and ProTaper Universal in curved canals. J Endod 2015;41(10):1718-1724

4 Parashos P, Gordon I, Messer HH. Factors influencing defects of rotary nickel-titanium endodontic instruments after clinical use. J Endod 2004;30(10):722-725

5 Alcalde MP, Duarte MAH, Bramante CM, et al. Cyclic fatigue and torsional strength of three different thermally treated reciprocating nickel-titanium instruments. Clin Oral Investig 2018;22(4):1865-1871

6 Frota MM, Bernardes RA, Vivan RR, Vivacqua-Gomes N, Duarte MAH, Vasconcelos BC. Debris extrusion and foraminal deformation produced by reciprocating instruments made of thermally treated NiTi wires. J Appl Oral Sci 2018;26:e20170215

7 Shen Y, Coil JM, Zhou H, Zheng Y, Haapasalo M. HyFlex nickel-titanium rotary instruments after clinical use: metallurgical properties. Int Endod J 2013;46(8):720-729

8 Tanomaru-Filho M, Galletti Espir C, Carolina Venção A, Macedo-Serrano N, Camilo-Pinto J, Guerreiro-Tanomaru J. Cyclic fatigue resistance of heattreated nickel-titanium instruments. Iran Endod J 2018;13(3):312-317

9 Pinto JC, Pivoto-João MM, Espir CG, Ramos MLG, Guerreiro-Tanomaru JM, Tanomaru-Filho M. Micro-CT evaluation of apical enlargement of molar root canals using rotary or reciprocating heat-treated NiTi instruments. J Appl Oral Sci 2019;27:e20180689

10 Arruda EDS, Sponchiado-Júnior EC, Pandolfo MT, Fredson MAC, Roberi Garcia LDF, Marques AA. Apical transportation and centering ability after root canal filling removal using reciprocating and continuous rotary systems: a CBCT study. Eur J Dent 2019;13(4):613-618

11 Zuolo AS, Mello JE Jr, Cunha RS, Zuolo ML, Bueno CE. Efficacy of reciprocating and rotary techniques for 
removing filling material during root canal retreatment. Int Endod J 2013;46(10):947-953

12 Alves FR, Marceliano-Alves MF, Sousa JC, Silveira SB, Provenzano JC, Siqueira JF Jr. Removal of root canal fillings in curved canals using either reciprocating single- or rotary multi-instrument systems and a supplementary step with the XP-Endo Finisher. J Endod 2016;42(7):1114-1119

13 Rodrigues CT, Duarte MA, de Almeida MM, de Andrade FB, Bernardineli N. Efficacy of CM-wire, M-wire, and nickel-titanium instruments for removing filling material from curved root canals: a micro-computed tomography study. J Endod 2016;42(11):1651-1655

14 Machado AG, Guilherme BPS, Provenzano JC, et al. Effects of preparation with the Self-Adjusting File, TRUShape and XP-endo Shaper systems, and a supplementary step with XP-endo Finisher $\mathrm{R}$ on filling material removal during retreatment of mandibular molar canals. Int Endod J 2019;52(5):709-715

15 Martins MP, Duarte MA, Cavenago BC. Kato AS, da Silveira Bueno CE. Effectiveness of the ProTaper Next and Reciproc systems in removing root canal filling material with sonic or ultrasonic irrigation: a micro-computed tomographic study. J Endod 2017;43(3):467-471

16 Rossi-Fedele G, Ahmed HM. Assessment of root canal filling removal effectiveness using micro-computed tomography: a systematic review. J Endod 2017;43(4):520-526

17 Azim AA, Wang HH, Tarrosh M, Azim KA, Piasecki L. Comparison between single-file rotary systems: part 1-efficiency, effectiveness, and adverse effects in endodontic retreatment. J Endod 2018;44(11):1720-1724

18 De-Deus G, Belladonna FG, Zuolo AS, et al. 3-dimensional ability assessment in removing root filling material from pair-matched oval-shaped canals using thermal-treated instruments. J Endod 2019;45(9):1135-1141

19 Canali LCF, Duque JA, Vivan RR, Bramante CM, Só MVR, Duarte MAH. Comparison of efficiency of the retreatment procedure between Wave One Gold and Wave One systems by Micro-CT and confocal microscopy: an in vitro study. Clin Oral Investig 2019;23(1):337-343

20 Delai D, Jardine AP, Mestieri LB, et al. Efficacy of a thermally treated single file compared with rotary systems in endodontic retreatment of curved canals: a micro-CT study. Clin Oral Investig 2019;23(4):1837-1844

21 Barreto MS, Rosa RA, Santini MF, et al. Efficacy of ultrasonic activation of $\mathrm{NaOCl}$ and orange oil in removing filling material from mesial canals of mandibular molars with and without isthmus. J Appl Oral Sci 2016;24(1):37-44

22 de Souza PF, Goncalves LCO, Marques AAF, Junior ECS, Garcia LDFR, de Carvalho FMA. Root canal retreatment using reciprocating and continuous rotary nickel-titanium instruments. Eur J Dent 2015;9(2):234-239

23 Gergi R, Sabbagh C. Effectiveness of two nickel-titanium rotary instruments and a hand file for removing gutta-percha in severely curved root canals during retreatment: an ex vivo study. Int Endod J 2007;40(7):532-537

24 Elayouti A, Dima E, Judenhofer MS, Löst C, Pichler BJ. Increased apical enlargement contributes to excessive dentin removal in curved root canals: a stepwise microcomputed tomography study. J Endod 2011;37(11):1580-1584
25 Vertucci FJ. Root canal anatomy of the human permanent teeth. Oral Surg Oral Med Oral Pathol 1984;58(5):589-599

26 Pruett JP, Clement DJ, Carnes DL Jr. Cyclic fatigue testing of nickel-titanium endodontic instruments. J Endod 1997;23(2):77-85

27 Alcalde MP, Tanomaru-Filho M, Bramante CM, et al. Cyclic and torsional fatigue resistance of reciprocating single files manufactured by different nickel-titanium alloys. J Endod 2017;43(7):1186-1191

28 da Frota MF, Espir CG, Berbert FL, et al. Comparison of cyclic fatigue and torsional resistance in reciprocating single-file systems and continuous rotary instrumentation systems. J Oral Sci 2014;56(4):269-275

29 Siqueira JF Jr, Rôças IN, Ricucci D, Hülsmann M. Causes and management of post-treatment apical periodontitis. $\mathrm{Br}$ Dent J 2014;216(6):305-312

30 Vieira AR, Siqueira JF Jr, Ricucci D, Lopes WS. Dentinal tubule infection as the cause of recurrent disease and late endodontic treatment failure: a case report. J Endod 2012;38(2):250-254

31 Shahabinejad H, Ghassemi A, Pishbin L, Shahravan A. Success of ultrasonic technique in removing fractured rotary nickel-titanium endodontic instruments from root canals and its effect on the required force for root fracture. J Endod 2013;39(6):824-828

32 Bago I, Plotino G, Katić M, Ročan M, Batinić M, Anić I. Evaluation of filling material remnants after basic preparation, apical enlargement and final irrigation in retreatment of severely curved root canals in extracted teeth. Int Endod J 2020;53(7):962-973

33 Plotino G, Grande NM, Tocci L, Testarelli L, Gambarini G. Influence of different apical preparations on root canal cleanliness in human molars: A SEM study. J Oral Maxillofac Res 2014;5(2):e4

34 Srikanth P, Krishna AG, Srinivas S, Reddy ES, Battu S, Aravelli S. Minimal apical enlargement for penetration of irrigants to the apical third of root canal system: a scanning electron microscope study. J Int Oral Health 2015;7(6):92-96

35 Rodrigues RCV, Zandi H, Kristoffersen AK, et al. Influence of the apical preparation size and the irrigant type on bacterial reduction in root canal-treated teeth with apical periodontitis. J Endod 2017;43(7):1058-1063

36 Capar ID, Kaval ME, Ertas H, Sen BH. Comparison of the cyclic fatigue resistance of 5 different rotary pathfinding instruments made of conventional nickel-titanium wire, M-wire, and controlled memory wire. J Endod 2015;41(4):535-538

37 Gambarini G, Piasecki L, Ropini P, Miccoli G, Nardo DD, Testarelli L. Cone-beam computed tomographic analysis on root and canal morphology of mandibular first permanent molar among multiracial population in Western European population. Eur J Dent 2018;12(3):434-438

38 Siqueira JF, Jr, Rôças IN. Clinical implications and microbiology of bacterial persistence after treatment procedures. J Endod 2008;34(11):1291-1301.e3

39 Silva EJNL, Ferreira VM, Silva CC, Herrera DR, De-Deus G, Gomes BP. Influence of apical enlargement and complementary canal preparation with the Self-Adjusting File on endotoxin reduction in retreatment cases. Int Endod J 2017;50(7):646-651 